\title{
Epidemiology of musculoskeletal symptoms, rheumatologic disorders, and disability in the Zoroastrian population in Yazd, Iran: a WHO-ILAR COPCORD study (stage 1)
}

Ali Dehghan ${ }^{1}$, Hossein Soleimani Salehabadi ${ }^{1}$, Ahmadreza Jamshidii ${ }^{2}$ Zohre Kamali ${ }^{3}$, Mojgan Mali ${ }^{4}$, Seyedeh Tahereh Faezi ${ }^{2^{*}}$, Azarakhsh Baghdadi ${ }^{2^{*}}$ (D), Sogol Alesaeidi ${ }^{5}$, Fatemeh Sahraei ${ }^{5}$, Niloufar Azizi ${ }^{6}$, Sanaz Zand ${ }^{7}$, Sara Sadat Yasini ${ }^{5}$, Maryam Namazi ${ }^{6}$, Atefe Daya ${ }^{7}$, Ryan Nazemian ${ }^{8}$, Farimah Shamsi ${ }^{7}$, Mohammad Nejadhosseinian ${ }^{2}$ and Fereydoun Davatchi ${ }^{2}$

\begin{abstract}
Background: The purpose of this study was to determine the prevalence of musculoskeletal complaints, rheumatologic diseases, and disability among the Zoroastrian population in Iran.

Methods: The city of Yazd, in central Iran was selected for this study, with the highest population of Zoroastrians in Iran. Subjects were selected by cluster sampling of 9 neighborhoods populated with Zoroastrians. Subjects $\geq 15$ years old were interviewed by trained interviewers in their houses. The validated Farsi translation of Community Oriented Program for the Control of Rheumatic Disease (COPCORD) Core Questionnaire (CCQ) was used for this study. Subjects with musculoskeletal complaints (pain, stiffness and/or swelling) were examined by a rheumatologist. Laboratory tests and radiographic exams were performed when deemed necessary.

Results: Two-thousand subjects were interviewed during a 12-month period, of which 956 were male, and 1044 were female. The mean age was $41.1 \pm 18.3$ years (95\%Cl: 40.3-41.9). 36.9\% of the subjects had university-level education. In the 7 days prior to the interview, $27.6 \%$ of the subjects had musculoskeletal complaints, with the knee, dorsolumbar spine, and shoulder being the most common sites of complaints. The most common rheumatologic diagnoses were osteoarthritis (21.5\%) and low back pain (10.3\%). Rheumatoid arthritis was diagnosed in 1.2\% of the subjects.

Conclusions: The epidemiology of musculoskeletal complaints and rheumatologic disorders was inconsistent with previous COPCORD studies in Iran, with a lower prevalence of musculoskeletal complaints in general, lower rates of Behçet and lupus, and a higher prevalence of rheumatoid arthritis. The findings of this study can be for development of better prevention, screening, and treatment programs for the vulnerable population of Zoroastrians in Iran.
\end{abstract}

Keywords: COPCORD, Community-based epidemiology, Rheumatic diseases, Musculoskeletal disorders, Disability, Zoroastrians

\footnotetext{
*Correspondence: tfaezi@sina.tums.ac.ir; azarakhsh.baghdadi88@gmail.com

${ }^{2}$ Rheumatology Research Center, Tehran University of Medical Sciences, North Amirabad Street, Tehran 1411713137, Iran

Full list of author information is available at the end of the article
}

C C The Author(s). 2021 Open Access This article is licensed under a Creative Commons Attribution 4.0 International License, which permits use, sharing, adaptation, distribution and reproduction in any medium or format, as long as you give appropriate credit to the original author(s) and the source, provide a link to the Creative Commons licence, and indicate if changes were made. The images or other third party material in this article are included in the article's Creative Commons licence, unless indicated otherwise in a credit line to the material. If material is not included in the article's Creative Commons licence and your intended use is not permitted by statutory regulation or exceeds the permitted use, you will need to obtain permission directly from the copyright holder. To view a copy of this licence, visit http://creativecommons.org/licenses/by/4.0/ The Creative Commons Public Domain Dedication waiver (http://creativecommons.org/publicdomain/zero/1.0/) applies to the data made available in this article, unless otherwise stated in a credit line to the data. 


\section{Background}

The Community Oriented Program for Control of Rheumatic Diseases (COPCORD) was established in 1981 by WHO (World Health Organization) and ILAR (International League of Associations of Rheumatology), focusing on pain and disability caused by rheumatologic disorders in the developing countries. This initiative was launched with the aims of recognition, prevention, and control of rheumatologic disorders in communities with limited infrastructure and financial resources. To date, 21 countries have undertaken stage 1 of the program, which sought to evaluate at least 1500 people over 15 years of age. While being a nongovernmental project relying on local funds and resources, COPCORD has proven to be an outstanding endeavor to improve our understanding of the burden of musculoskeletal disorders in communities with the least access to healthcare. More information about the program's agenda is available on the COPCORD website (www.copcord.org).

Iran is situated in the crossroads of the East and West and is in the middle of the ancient silk route. Due to its unique geographic, demographic, and political situation in the world, as well as good healthcare infrastructure, Iran was an interesting addition to the COPCORD project. To date, multiple COPCORD studies have been performed in Iran as part of stage 1 of the project. A pilot study [1] was followed by an urban study in Tehran [2]. Tehran, the capital city of Iran, was selected as the first urban center for the study, mainly because it represented all ethnic groups in the country and the availability of resources [2]. With 10,291 subjects, it was one of the most successful COPCORD studies to date and was followed by a rural study in Tuyserkan [3]. Zahedan, a city in the less developed southeast of Iran, was the subject of the second urban study [4]. Sanandaj, situated in northwestern Iran, with a mainly Kurd population, was the next COPCORD urban field [5]. The fourth study was performed in Yazd, and the combined data from all four urban COPCORD sites have been analyzed [6].

As a protected minority group, the Zoroastrian community has inhabited central Iran, particularly the Yazd province, for centuries. While efforts have been made to promote inclusion and diversity, discrimination still exists against protected communities. The prevalence of mental illnesses, including depression and anxiety, has a higher incidence among Zoroastrian communities [7]. The purpose of this study was to report the results of the fourth urban COPCORD study, conducted among the Zoroastrian population in Yazd, Iran, to determine the prevalence of musculoskeletal complaints, rheumatologic diseases, and disability among the Zoroastrian population in Iran.

\section{Methods}

Yazd, the capital city of the Yazd province, was selected for this study. Yazd, with a population of 529,673, was selected due to its unique ethnic distribution. Iran has a heterogeneous ethnic distribution overall, with $75.4 \%$ of the population being Caucasians and around 22\% Turks. Semites constitute the third-largest population, with $2.6 \%$ of the population, and include Arabs, Jews, and Assyrians. Zoroastrians are another Caucasian minority, mainly concentrated in Yazd. While most of the population in Iran are of mixed descent, the Zoroastrian population of Yazd has maintained a semi-closed community with a very low rate of intermarriage. The Zoroastrians have not been the subject of a community-based study before, with a knowledge void regarding the epidemiology of diseases, particularly common musculoskeletal symptoms and rheumatologic disorders.

\section{Sampling plan}

The population of Zoroastrians in Iran stood at 25,271 according to the latest census results, with the vast majority residing in the Yazd province [8]. Nine neighborhoods with a high Zoroastrian population were chosen, and subjects were recruited by cluster sampling in those neighborhoods.

\section{Questionnaire}

The Farsi translation of the COPCORD Core Questionnaire (CCQ) was used to screen subjects for musculoskeletal complaints [9]. This translation has been validated and has been shown to be reliable and reproducible [1]. The following sections of the CCQ were administered to all individuals as described previously: sections A (background information), B (work history), $\mathrm{C} 1$ (pain, tenderness, or stiffness in the last week), D (functional disability), G (evaluation), and $\mathrm{H}$ (extra-articular symptoms of rheumatic diseases (aphthous ulcers, blurred vision, etc.), including Behçet's disease) $[1,2,5]$. The detailed methodology of subject selection and administration of the test have been reported previously [1].

\section{Data collection}

Two physicians (general practitioners) who knew the local community were trained on the details of COPCORD methodology at the Rheumatology Research Center of Tehran University of Medical Sciences. A training workshop was held for 12 interviewers in Yazd by the practitioners and a member of the COPCORD team from the Rheumatology Research Center. Also, Bachelor students from Yazd University of Medical Sciences were recruited to supervise the data collection team and monitor the process, fill the special evaluation checklist, and manage the groups. 


\section{Pilot study}

A Pilot study was performed to evaluate the possibility and limitations of the COPCORD study. Two members from the RRC in Tehran who were familiar with the study model travelled to Yazd to overlook the pilot study. Fifty subjects were randomly selected. The Pilot study was carried out on the weekend (Friday in Iran). The selected individuals were informed about the goals of the study, and were then interviewed by the team. Subjects who had musculoskeletal complaints or a history of oral ulcer were referred to the clinic for further evaluation. Two rheumatologists were present in the clinic and evaluated the patients, including a detailed history and physical examination, and laboratory and imaging studies if needed.

\section{Data collection}

The selected cluster was visited by the team consisting of the project manager, a rheumatologist, interviewers, and a lab technician, 2 days each week. Households were selected randomly within each cluster based on postal codes, and a minimum of 250 subjects were interviewed in each cluster to ensure a random distribution. The identified households were visited, and a thorough explanation about the study was given. Then, a form was completed for each family, asking about the information of household members 15 years of age or older. For absent individuals, the team went back to the same household for two consecutive days to collect data if possible. Filled questionnaires were then forwarded to the team head, to be checked for quality of data collection and refer individuals who needed a physical examination to the rheumatologist. Blood samples were taken during the same visit if necessary. Similar to previous COPCORD studies, rheumatologic diseases and syndromes were diagnosed based on their accepted criteria (SLE, Behçet's disease, RA, etc.), while mechanical disorders (e.g., osteoarthritis, rotator cuff disorders) were assigned based on the visiting rheumatologist's diagnosis [6].

\section{Quality control}

All interviewers underwent regular quality control checks from the project manager. Furthermore, all of the forms and examination sheets were checked by the team head in the field. CCQs were rechecked later and were evaluated for any missing data or errors.

\section{Data analysis}

Descriptive data were analyzed by survey data analysis methods with regard to age, sex, and weight of the cluster. Statistical analysis was performed with IBM SPSS Statistics for Windows, version 23.0 (IBM, Armonk, NY) and STATA (StataCorp, College Station, TX, USA). The prevalence of musculoskeletal disorders was adjusted to age-sex distribution of the study population from the 2011 Census [10]. Prevalence rates were presented as percentages (95\% confidence interval $[\mathrm{CI}]$ ).

\section{Power}

Previous COPCORD studies performed in Iran have shown a $30-50 \%$ prevalence of musculoskeletal complaints, $15-25 \%$ for degenerative joint diseases, and approximately $1 \%$ for rheumatologic disorders $[6,11,12]$. Therefore, with a $5 \%$ type I error and an absolute error of $5 \%$, this study would need $>138$ individuals for a disease with $10 \%$ prevalence (e.g., musculoskeletal complaints), and $>1382$ individuals for $1 \%$ prevalence (e.g., rheumatologic diagnoses). Therefore, a minimum sample size of 1500 was set for this study.

\section{Results}

The data collection phase was completed in 12 months. At the end of the study, 2000 eligible subjects were interviewed. Among them, 645 (374 female, 271 male) needed a physical examination by a rheumatologist. The male to female ratio was 0.91:1, with 956 (47.8\%) male and 1044 (52.2\%) female subjects. The 2011 Yazd census showed a $1.06: 1$ male $(51.4 \%)$ to female $(48.6 \%)$ ratio. All subjects in this study were Caucasians of Zoroastrian ancestry. The age distribution in comparison to the 2011 census is illustrated in Fig. 1, with gender details in Table 1.

\section{Education level}

$1.1 \%$ of the subjects were illiterate. $25.7 \%$ had some primary school to some high school education, 36.2\% had a high school diploma, and $37 \%$ of the subjects had a university-level education

\section{Musculoskeletal complaints}

Overall, 27.6\% of the subjects had at least one episode of musculoskeletal complaints during the last 7 days of the interview, which included patients with continuous or episodic complaints. Musculoskeletal complaints were more frequent among females (37.1\%) compared to males (17.2\%). The interviewees were also asked for musculoskeletal complaints in the past ( $>7$ days ago), of which $19.1 \%$ answered positively. Table 2 summarizes the details of musculoskeletal complaints broken down by age groups.

\section{Joint distribution of musculoskeletal complaints (pain, swelling, and stiffness)}

Shoulder 9.3\% (95\% confidence interval: 7.9-10.6), elbow 4.4\% (95\% CI: 3.4-5.3), and wrist 5.1\% (95\% CI: 4.2-6.1), were the most common sites of musculoskeletal complaints. Details and gender-specific data is summarized in Table 3. 


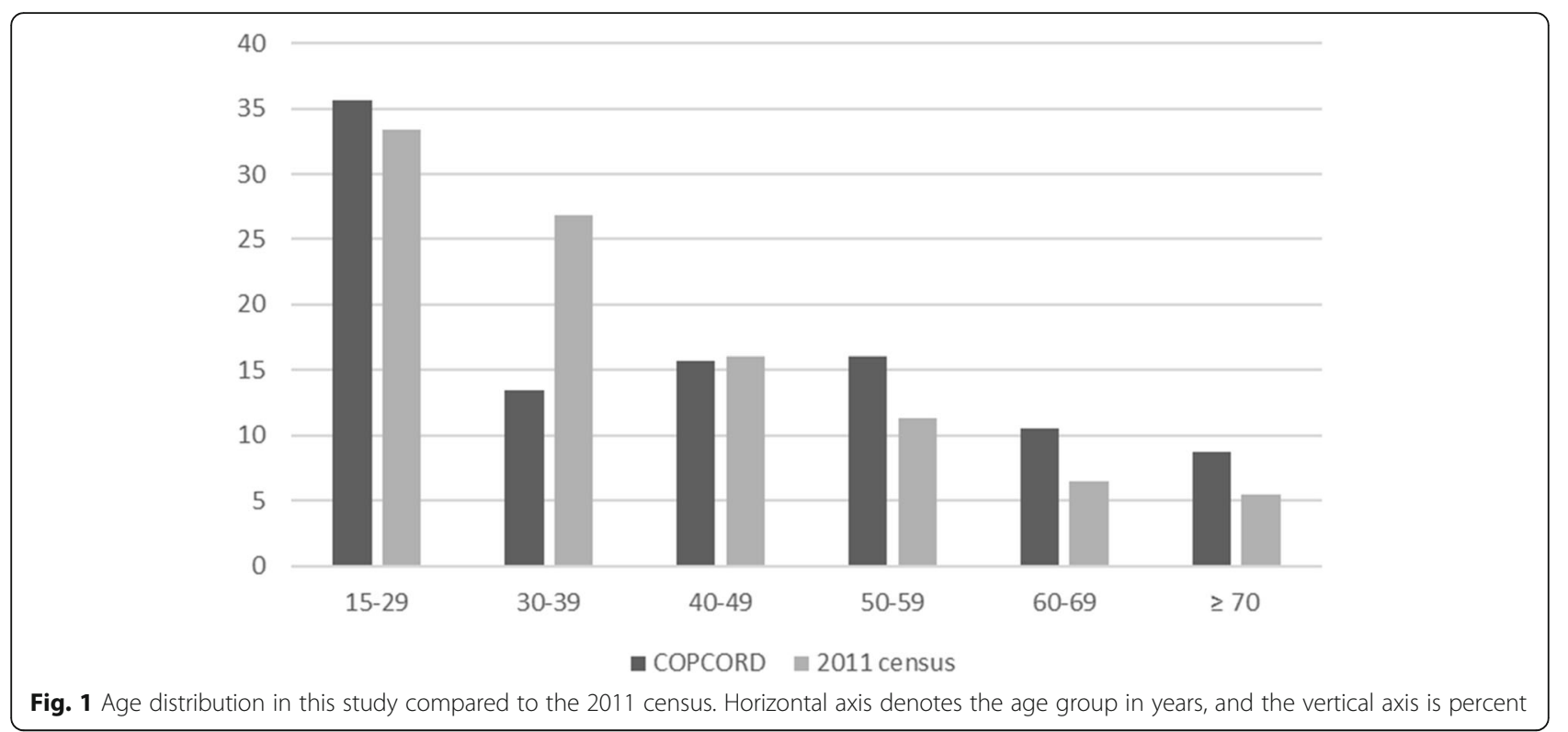

In patients who had musculoskeletal complaints in the past ( $>7$ days prior to the interview), knee (17.3\%), dorsolumbar spine $(15.9 \%)$, and shoulder $(10.4 \%)$ were the most common complaint sites.

\section{Diagnosed diseases}

Degenerative joint disease was diagnosed in $21.5 \%$ of the subjects, with knee osteoarthritis being the most common site in both males and females, followed by hip and neck. Among other mechanical disorders, low back pain was the most prevalent $(10.3,95 \% \mathrm{CI}$ : 911.6), followed by sciatica (5.1, 95\%CI: 4.2-6.2). The prevalence of tendinitis and bursitis in total was $5.2 \%$ (95\%CI: 4.3-6.2). Inflammatory rheumatologic diseases diagnosed in the subjects included Rheumatoid Arthritis (1.2, 95\%CI: 0.8-1.7), seronegative spondyloarthropathies $(0.7,95 \% \mathrm{CI}: 0.4-1.1)$, fibromyalgia (0.4, 95\%CI: $0.1-0.6)$, and gout $(0.3,95 \% \mathrm{CI}: 0.1-0.5)$. Of note, no cases of systemic lupus erythematous and Behçet disease were diagnosed in this study. Table 4 summarizes the diagnosed diseases in this study.

\section{Disability}

At the time of the interview, 254 subjects $(12.7,95 \% \mathrm{CI}$ : 11.5-14.3) reported some disability in performing activities of daily living (ADL) caused by musculoskeletal symptoms. Disability was more prevalent in females (18, 95\%CI: 15.5-20.2) than males (6.9, 95\%CI: 5.4-8.6). Details of ADL broken down by the severity of disability are summarized in Table 5.

\section{Discussion}

This study aimed to determine the prevalence of musculoskeletal complaints and rheumatologic disorders among the Zoroastrian population in Yazd, Iran. To the best of our knowledge, this is the first study of its kind in this population. The Zoroastrians are a protected minority in Iran, along with Armenians, Assyrians, and Persian Jews. The large majority of Zoroastrians in Iran live in the Yazd city, and due to generations of relative inbreeding, they have maintained their unique genetic makeup of their Aryan ancestors. In the last decades, low birth rates have affected the growth of this

Table 1 Age distribution categorized by gender

\begin{tabular}{|c|c|c|c|c|c|c|c|c|}
\hline \multirow{2}{*}{$\begin{array}{l}\text { Age } \\
\text { (years) }\end{array}$} & \multicolumn{4}{|c|}{ Male } & \multicolumn{4}{|c|}{ Female } \\
\hline & $\mathrm{N}$ & $\%$ & $95 \% \mathrm{Cl}$ & Census $\%$ & $\mathrm{~N}$ & $\%$ & $95 \% \mathrm{Cl}$ & Census \% \\
\hline $15-29$ & 369 & 38.6 & $35.4-41.8$ & 33.2 & 342 & 32.8 & 29.9-35.7 & 33.7 \\
\hline 30-39 & 128 & 13.4 & $11.2-15.5$ & 27.1 & 141 & 13.5 & $11.5-15.5$ & 26.8 \\
\hline 40-49 & 137 & 14.3 & $12.1-16.4$ & 16.5 & 177 & 17 & $14.6-19.1$ & 15.9 \\
\hline 50-59 & 138 & 14.4 & $12-16.7$ & 11.6 & 184 & 17.6 & $15.3-19.9$ & 11.1 \\
\hline $60-69$ & 101 & 10.6 & $8.6-12.6$ & 6.4 & 108 & 10.3 & $8.5-12.2$ & 6.6 \\
\hline$\geq 70$ & 83 & 8.7 & $6.9-10.6$ & 5.2 & 92 & 8.8 & $7.2-10.6$ & 5.9 \\
\hline Total & 956 & 100 & & & 1044 & 100 & & \\
\hline
\end{tabular}


Table 2 Musculoskeletal complaints in the subjects of this study, broken down by age, and complaint

\begin{tabular}{|c|c|c|c|c|c|c|c|c|}
\hline \multirow[t]{2}{*}{ Age } & \multicolumn{2}{|c|}{ Overall complaints } & \multicolumn{2}{|l|}{ Pain } & \multicolumn{2}{|c|}{ Swelling } & \multicolumn{2}{|c|}{ Stiffness } \\
\hline & $\%$ & $\mathrm{Cl}$ & $\%$ & $\mathrm{Cl}$ & $\%$ & $\mathrm{Cl}$ & $\%$ & $\mathrm{Cl}$ \\
\hline $15-29$ & 9 & $7-11.1$ & 9 & $6.9-11$ & 1.3 & $0.6-2.1$ & 2 & $1-3.1$ \\
\hline $30-39$ & 18.2 & $13.8-23$ & 18.2 & $13.8-23$ & 3 & $1.1-5.2$ & 3.7 & $1.5-5.9$ \\
\hline $40-49$ & 33.4 & $28-38.9$ & 32.8 & $27.7-37.9$ & 7.6 & $5.1-10.8$ & 11.5 & $8.3-15.6$ \\
\hline $50-59$ & 39.4 & $33.9-45.3$ & 38.2 & $32.9-43.5$ & 12.7 & $9-16.5$ & 13.7 & $9.9-17.4$ \\
\hline $60-69$ & 48.8 & $42.1-56.5$ & 48.8 & $41.6-56$ & 19.1 & $14.4-24.9$ & 17.2 & $12-22.5$ \\
\hline$\geq 70$ & 59.4 & $52-66.3$ & 59.4 & $52-66.9$ & 22.9 & $16.6-29.7$ & 21.7 & $16-28$ \\
\hline All ages & 27.6 & $25.8-29.5$ & 27.3 & $25-29$ & 8.1 & $6.7-9.5$ & 8.9 & $7.8-10.3$ \\
\hline
\end{tabular}

Cl 95\% confidence interval

population in Iran. The results of this study contribute to the knowledge of the epidemiology of musculoskeletal symptoms, rheumatologic disorders, and disabilities in this vulnerable population.

The age distribution in this study was slightly different than the 2011 census results, and as such, data were adjusted for age and sex. It should be noted that the mean age of the Zoroastrian population in Iran is higher than the average population and is not due to a sampling error. Interestingly, $36.9 \%$ of the interviewees in this study had higher education levels (university-level education). This is higher than the previous COPCORD studies in Tehran (19.9\%) [2], Sanandaj (21.5\%) [5], and Zahedan (16.9\%) [4], and is twice as high as the national average [13].

Musculoskeletal complaints during the 7 days preceding the interview were observed in $27.6 \%$ of the subjects, with pain being the most common complaint (27.3\%). Among the Iran COPCORD studies, this is the lowest prevalence of musculoskeletal complaints [1-5], and is more in line with Australia [14], Kuwait [15], and Mexico [16] data. Knee, followed by dorsolumbar spine and shoulder, was the most common

Table 3 Gender distribution of musculoskeletal complaints based on site of symptoms

\begin{tabular}{llll}
\hline Joint & Men & Women & All \\
\hline Shoulder & $4.6(3.3-6.1)$ & $13.6(11.5-15.6)$ & $9.3(7.9-10-6)$ \\
Elbow & $2.2(1.4-3.1)$ & $6.3(4.8-7.9)$ & $4.4(3.4-5.3)$ \\
Wrist & $1.8(1-2.7)$ & $8.2(6.5-9.9)$ & $5.1(4.2-6.1)$ \\
Hand & $2.4(1.5-3.5)$ & $10.2(8.3-12.1)$ & $6.5(5.5-7.6)$ \\
Hip & $2.6(1.7-3.8)$ & $8.3(6.7-10.2)$ & $5.6(4.6-6.6)$ \\
Knee & $9.9(7.9-11.9)$ & $23.2(20.7-25.8)$ & $16.9(15.3-18.5)$ \\
Ankle & $2.8(1.9-4.1)$ & $7.8(6.1-9.6)$ & $5.4(4.4-6.4)$ \\
Foot & $1.9(1-2.7)$ & $6.6(5.2-8.2)$ & $4.4(3.5-5.3)$ \\
Cervical Spine & $4(2.8-5.3)$ & $12.7(10.7-14.6)$ & $8.5(7.3-9.8)$ \\
Dorsolumbar & $7.6(5.9-9.4)$ & $19.3(17-21.6)$ & $13.7(12.2-15.2)$ \\
All sites & $\mathbf{1 7 . 2 ( 1 4 . 6 - 1 9 . 6 )}$ & $\mathbf{3 7 . 1}(\mathbf{3 4 - 4 0 . 3 )}$ & $\mathbf{2 7 . 6}(\mathbf{2 5 . 8 - 2 9 . 5 )}$
\end{tabular}

Data is presented as percent ( $95 \%$ confidence interval) site of a rheumatologic complaint. This has been a consistent finding in previous Iranian and international COPCORD studies, which highlights the high strains the current living conditions place on the knee (Table 6).

Along the same lines, osteoarthritis was found to be the most common rheumatologic disease in this study, with a total of $21.5 \%$ prevalence, which was similar to previous Iran COPCORD studies. However, international COPCORD studies have a consistently lower prevalence of OA, which might be the result of heterogeneous criteria for the diagnosis of the condition. OA of the knee and hip cause the greatest burden to the population due to pain and stiffness [32]. Knee and hip were the most common sites of OA in this study, similar to previous studies.

Among other mechanical disorders, low back pain was a common diagnosis, and with a $10.3 \%$ prevalence, is substantially lower than previous Iran COPCORD studies [1-5], and is more similar to Cuba [22], India [25], Malaysia [27], and Vietnam [31] studies. The Zoroastrians in Iran are highly educated and are less employed in manual labor jobs, which might be the reason for the relatively low rate of low back pain.

Rheumatoid arthritis was the most common inflammatory disease diagnosed in this study. With a prevalence of $1.2 \%$, RA has the highest prevalence in the Iran COPCORD studies, and most international studies. Only Mexico has reported a higher rate (1.5\%) [16], and Cuba has also reported a similar prevalence (1.2\%) [22]. Interestingly, gout was also more common in this study compared to previous Iranian studies. We found a prevalence of $0.4 \%$ for gout, with higher rates only reported in the Australian COPCORD studies [14, 17]. This might be the result of a higher socioeconomic status of the Zoroastrians, with higher consumption of meat and other gout risk factors. Spondyloarthropathies were also common in this study (0.7\%) compared to previous Iran and international studies, which might be the result of the genetic makeup of this population, which is different than other Iranian ethnicities. 
Table 4 Diagnosed diseases in this COPCORD study

\begin{tabular}{|c|c|c|c|}
\hline Diagnosis & Male \% $(95 \% \mathrm{Cl})$ & Female $\%(95 \% \mathrm{Cl})$ & All \% $(95 \% \mathrm{Cl})$ \\
\hline \multicolumn{4}{|l|}{ Osteoarthritis } \\
\hline Total & $12.7(10.8-15)$ & $29.5(26.9-32.4)$ & $21.5(19.7-23.3)$ \\
\hline Hip & $4.1(2.9-5.3)$ & $9.8(8.1-11.7)$ & $7.1(6-8.2)$ \\
\hline Knee & $8.8(7.1-10.5)$ & $19.7(17.4-22.1)$ & $14.5(12.9-16)$ \\
\hline Hand & $2.1(1.2-3)$ & $6(4.6-7.6)$ & $4.2(3.3-5)$ \\
\hline Neck & $2.5(1.6-3.5)$ & $10(8.2-11.8)$ & $6.4(5.4-7.6)$ \\
\hline \multicolumn{4}{|l|}{ Other mechanical disorders } \\
\hline Chondromalacia Patella & $1.5(0.7-2.4)$ & $1.6(0.9-2.4)$ & $1.6(1-2.1)$ \\
\hline Low back pain & $7.2(5.6-8.8)$ & $13(11-15.3)$ & $10.3(9-11.6)$ \\
\hline Carpal Tunnel Syndrome & $0.8(0.3-1.5)$ & $3.8(2.8-5)$ & $2.4(1.8-3)$ \\
\hline Trigger finger & $0.3(0-0.7)$ & $0.5(0.1-1)$ & $0.4(0.2-0.7)$ \\
\hline De Quervain Tenosynovitis & $0.3(0-0.7)$ & $0.7(0.2-1.2)$ & $0.5(0.3-0.9)$ \\
\hline Tennis elbow & $0.4(0.1-0.8)$ & $1.6(0.9-2.6)$ & $1.1(0.7-1.6)$ \\
\hline Golf Elbow & 0 & $0.4(0.1-0.8)$ & $0.2(0.1-0.4)$ \\
\hline Shoulder rotator cuff pathology & $1(0.4-1.8)$ & $2.9(2-3.8)$ & $2(1.5-2.7)$ \\
\hline Sciatica & $3.1(2.1-4.3)$ & $7(5.7-8.6)$ & $5.1(4.2-6.2)$ \\
\hline Cervical radiculopathy & $0.2(0-0.5)$ & $0.1(0-0.3)$ & $0.2(0-0.4)$ \\
\hline All Periarthritis & $3.1(2.1-4.2)$ & $7.1(5.1-8.6)$ & $5.2(4.3-6.2)$ \\
\hline \multicolumn{4}{|l|}{ Inflammatory/pain disorders } \\
\hline Fibromyalgia & $0.1(0-0.3)$ & $0.6(0.1-1.1)$ & $0.4(0.1-0.6)$ \\
\hline Gout & $0.2(0-0.5)$ & $0.3(0-0.7)$ & $0.3(0.1-0.5)$ \\
\hline Spondyloarthropathy & $0.9(0.4-1.6)$ & $0.4(0.1-0.8)$ & $0.7(0.4-1.1)$ \\
\hline Rheumatoid Arthritis & $0.2(0-0.5)$ & $2.1(1.2-3.1)$ & $1.2(0.8-1.7)$ \\
\hline Systemic Lupus erythematous & 0 & 0 & 0 \\
\hline Behçet disease & 0 & 0 & 0 \\
\hline
\end{tabular}

Cl 95\% Confidence interval

Table 5 Disability in activities of daily living among subjects in this study

\begin{tabular}{|c|c|c|c|c|c|c|c|c|}
\hline \multirow[t]{2}{*}{ ADL } & \multicolumn{2}{|c|}{ None } & \multicolumn{2}{|c|}{ Mild } & \multicolumn{2}{|c|}{ Moderate } & \multicolumn{2}{|c|}{ Severe } \\
\hline & $\%$ & $\mathrm{Cl}$ & $\%$ & $\mathrm{Cl}$ & $\%$ & $\mathrm{Cl}$ & $\%$ & $\mathrm{Cl}$ \\
\hline Dressing & 93.1 & $91.7-94.7$ & 5.4 & $4.4-6.5$ & 1.5 & $1-2.1$ & - & - \\
\hline Getting up & 87.5 & $86.3-88.8$ & 9 & $7.8-10.2$ & 3.3 & $2.5-4.1$ & 0.2 & $0.1-0.4$ \\
\hline Drinking & 98.1 & $96.5-99.8$ & 1.5 & $1-2$ & 0.3 & $0.1-0.5$ & 0.1 & $0-0.2$ \\
\hline Eating & 98.2 & $96.5-99.9$ & 1.3 & $0.8-1.8$ & 0.4 & $0.2-0.8$ & 0.1 & $0-0.2$ \\
\hline Walking & 89.2 & 87.7-90.6 & 7.6 & $6.5-8.7$ & 3.1 & $2.4-3.9$ & 0.1 & $0-0.2$ \\
\hline Bathing & 14.8 & $93.5-96.7$ & 3.5 & $2.6-4.3$ & 1.3 & $0.8-1.8$ & 0.1 & $0-0.2$ \\
\hline Turkish toilet (squat toilet) & 88.1 & $86.8-89.4$ & 4.5 & $3.6-5.4$ & 2.3 & $1.7-2.9$ & 5.1 & $4.2-6.2$ \\
\hline Taking an object on the floor & 89 & $69.6-90.4$ & 7.4 & $6.3-8.5$ & 2.9 & $2.2-3.7$ & 0.7 & $0.3-1$ \\
\hline Hanging cloths on a rope & 93.9 & $92.3-95.5$ & 3.8 & $2.9-4.7$ & 2 & $1.4-2.6$ & 0.3 & $0.1-0.5$ \\
\hline Going in and out a transport vehicle & 88.8 & $87.6-90.2$ & 8.2 & $7-9.4$ & 2.9 & $2.2-3.7$ & 0.1 & $0-0.2$ \\
\hline Cross leg sitting & 84.3 & $83.1-85.5$ & 3.8 & $2.9-4.6$ & 4.5 & $3.7-5.5$ & 7.4 & $6.3-8.6$ \\
\hline Praying & 95.8 & $94.2-97.4$ & 3.3 & $2.5-4$ & 0.8 & $0.4-1.2$ & 0.1 & $0-0.2$ \\
\hline Opening boxes & 96.5 & $94.9-98.2$ & 2 & $1.4-2.7$ & 1.1 & $0.7-1.6$ & 0.4 & $0.2-0.8$ \\
\hline
\end{tabular}




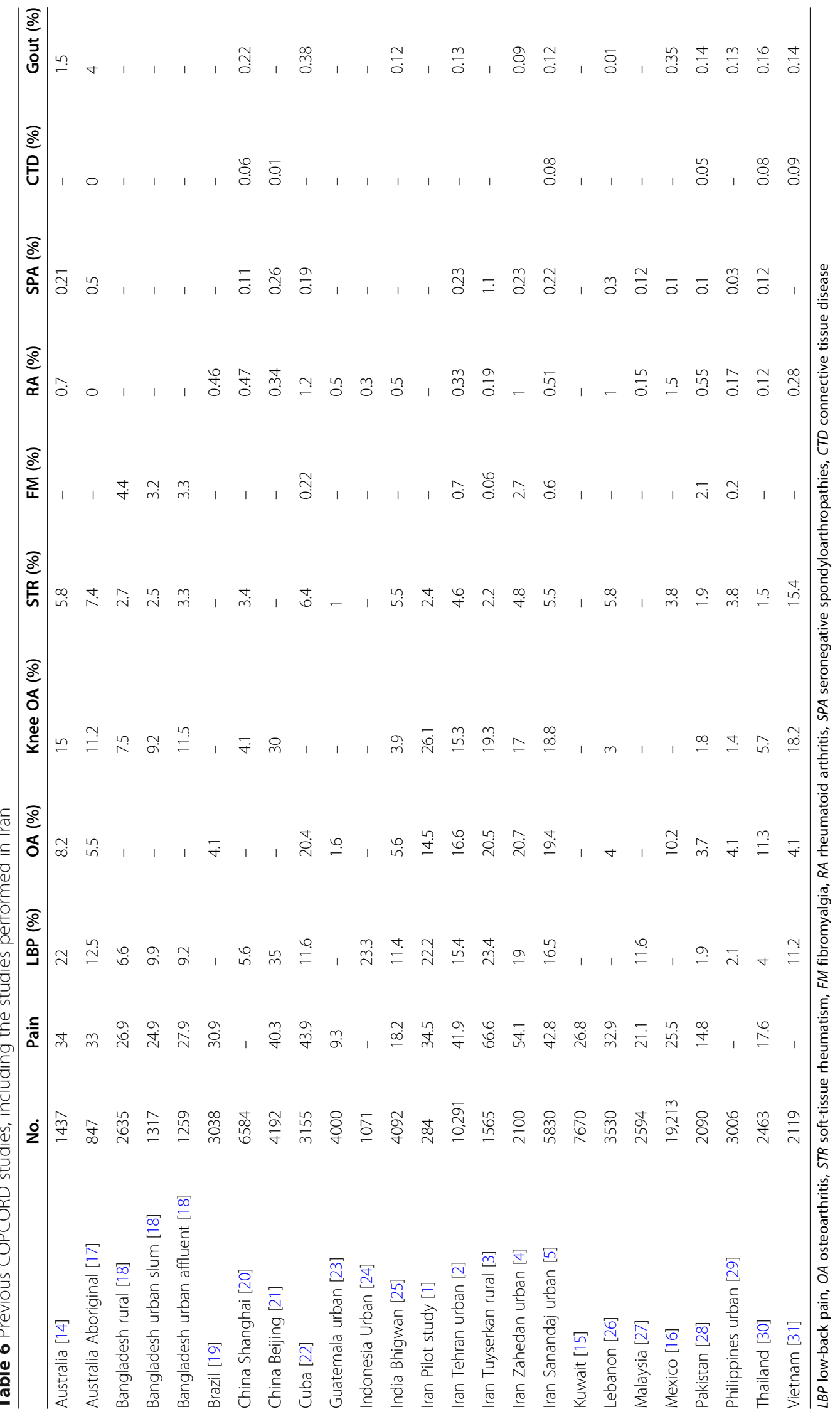


We did not find a single case of Behçet disease and SLE in this study, which was not the case with the previous COPCORD studies performed in Iran [1-5]. Iran has a high prevalence of Behçet disease [33]. Genetics play a significant role in Behçet disease [34], which again might be the reason for our findings.

The prevalence of disability in performing ADL was $12.7 \%$ in this study, with getting up and going in and out of a transport vehicle being the most common causes of mild disability, cross leg sitting and getting up the most common causes of moderate disability, and cross leg sitting, and Turkish toilet (squatting) were the most common causes of severe disability. Of note, the reported disability in this study was lower than previous COPCORD studies in Iran, which was reported at $22.4 \%$ in Zahedan [4], and $28.3 \%$ in the Sanandaj study [5].

This study has some limitations, including those inherent to the COPCORD methodology. The interview is time-consuming and exhaustive, and the accuracy of the responses may diminish with time. Also, although the CCQ is unique and has been standardized, some differences have been noted in the responses. For example, non-traumatic and traumatic pain have been interchangeably used in some studies, which weakens the reliability of the questionnaire. Additionally, the census data used to adjust data in this study were derived from the Yazd province records, which might be different than that of the Zoroastrian community. Finally, musculoskeletal complaints are subjectively surveyed, and mechanical disorders (e.g., osteoarthritis) is diagnosed by the visiting physician, with no predetermined criteria, which imposes some heterogeneity and bias to the study [35]. The strengths of this study include surveying a high percentage of the community (2000 out of 25,271 people). Also, a high response rate was observed, and a low dropout and refusal rate was recorded.

\section{Conclusions}

In conclusion, the results of this study suggest a distinct epidemiology of musculoskeletal complaints, rheumatologic diseases, and disability in the Zoroastrian population in Iran, with a lower rate of musculoskeletal complaints, osteoarthritis, and Behçet disease, and higher rates of gout and rheumatoid arthritis, compared to other studied populations in Iran. These findings can be used by local and national governments for the development of better prevention, screening, and treatment programs for the vulnerable population of Zoroastrians in Iran. Also, the unique genetic makeup of this population might be the subject of future studies on the genetic predisposition to common rheumatologic disorders.

\section{Abbreviations}

WHO: World Health Organization; ILAR: International League of Associations of Rheumatology; COPCORD: Community Oriented Program for Control of
Rheumatic Diseases; CCQ: COPCORD Core Questionnaire; MSK: Musculoskeletal; ADL: Activities of daily living; OA: Osteoarthritis; RA: Rheumatoid arthritis; SLE: Systemic lupus erythematous; LBP: Low-back pain; STR: Soft-tissue rheumatism; FM: Fibromyalgia;

SPA: Spondyloarthropathy; CTD: Connective-tissue disease

\section{Acknowledgements}

None.

\section{Authors' contributions}

Study design: AD, HSS, AJ, ZK, MM, SA, NA, SSY, RN, FD. Data Collection: AD, HSS, MM, SA, FS1, SZ, SSY, MN1, AD, FS2. Statistical Analysis: AJ, STF, AB, FS1, NA, SZ, MN1, RN, MN2. Manuscript drafting: STF, AB, FS1, FD, MN2. Revision of the manuscript: ZK, STF, AB, AD, FD, FS2. All authors have read and approved the final version of the manuscript.

\section{Funding}

This study was funded by Shahid Sadoughi University of Medical Sciences (Study ID 3036, IRB\# 148402). The funders had no direct role in the conduct of the reported study, analysis of the data or writing of the manuscript.

\section{Availability of data and materials}

The datasets used and/or analyzed during the current study are available from the corresponding author on reasonable request.

\section{Declarations}

\section{Ethics approval and consent to participate}

The study proposal was approved by the Ethics Committee of Shahid Sadoughi University of Medical Sciences (IRB\# 148402). It was previously approved by the National Ethics Committee on Medical Research of the Ministry of Health and Medical Education. All subjects were informed about the study goal and methodology and voluntarily participated in the study. They were enrolled in the study after having signed their informed consent. Written parental consent was obtained for minors, in addition to verbal assent of the subject. Participants could withdraw from the study at any stage (interview, physical exam, and paraclinical tests). All of the paraclinical costs were paid by the project budget. All subjects who had physical examination were sent a brief report about their health status. Laboratory results and $\mathrm{X}$-rays were also sent to the subjects.

\section{Consent for publication}

Not applicable.

\section{Competing interests}

The authors declare that they have no competing interests.

\section{Author details}

${ }^{1}$ Department of Internal Medicine, Shahid Sadoughi Hospital, Shahid Sadoughi University of Medical Sciences, Yazd, Iran. ${ }^{2}$ Rheumatology Research Center, Tehran University of Medical Sciences, North Amirabad Street, Tehran 1411713137, Iran. ${ }^{3}$ Diabetic Care Center, Shahid Sadoughi University, Yazd, Iran. ${ }^{4}$ Ziayee Hospital, Shahid Sadoughi University, Ardakan, Yazd, Iran. ${ }^{5}$ Shahid Sadoughi Hospital, Shahid Sadoughi University of Medical Sciences, Yazd, Iran. ${ }^{6}$ Feiz Hospital, Isfahan, Iran. ${ }^{7}$ Shahid Sadoughi University of Medical Sciences, Yazd, Iran. ${ }^{8}$ Clinical Translational Science PhD Program, Case Western Reserve University, Cleveland, OH, USA.

Received: 6 January 2021 Accepted: 7 July 2021

Published online: 02 November 2021

\section{References}

1. Davatchi F, Jamshidi A-R, Banihashemi AT. WHO-ILAR COPCORD pilot study in Tehran, Iran. J Rheumatol. 2006:33(8):1714.

2. Davatchi F, Jamshidi A-R, Banihashemi AT, Gholami J, Forouzanfar MH, Akhlaghi $M$, et al. WHO-ILAR COPCORD study (stage 1, urban study) in Iran. J Rheumatol. 2008;35(7):1384-90.

3. Davatchi F, Banihashemi AT, Gholami J, Faezi ST, Forouzanfar MH, Salesi M, et al. The prevalence of musculoskeletal complaints in a rural area in Iran: a WHO-ILAR COPCORD study (stage 1, rural study) in Iran. Clin Rheumatol. 2009;28(11):1267-74. https://doi.org/10.1007/s10067-009-1234-8. 
4. Sandoughi M, Zakeri Z, Tehrani Banihashemi A, Davatchi F, Narouie B, Shikhzadeh $A$, et al. Prevalence of musculoskeletal disorders in southeastern I ran: a WHO-ILAR COPCORD study (stage 1, urban study). Int J Rheum Dis. 2013;16(5):509-17. https://doi.org/10.1111/1756-185X.12110.

5. Moghimi N, Davatchi F, Rahimi E, Saidi A, Rashadmanesh N, Moghimi S, et al. WHO-ILAR COPCORD study (stage 1, urban study) in Sanandaj, Iran. Clin Rheumatol. 2015;34(3):535-43. https://doi.org/10.1007/s10067013-2430-0

6. Davatchi F, Sandoughi M, Moghimi N, Jamshidi AR, Tehrani Banihashemi A, Zakeri Z, et al. Epidemiology of rheumatic diseases in Iran from analysis of four COPCORD studies. Int J Rheum Dis. 2016;19(11):1056-62. https://doi. org/10.1111/1756-185X.12809.

7. Mirzaei M, Yasini Ardekani SM, Mirzaei M, Dehghani A. Prevalence of depression, anxiety and stress among adult population: results of Yazd health study. Iran J Psychiatry. 2019;14(2):137-46.

8. Foltz R. Zoroastrians in Iran: what future in the homeland? Middle East J. 2011;65(1):73-84. https://doi.org/10.3751/65.1.14

9. Goycochea-Robles MV, Sanin LH, Moreno-Montoya J, Alvarez-Nemegyei J, Burgos-Vargas R, Garza-Elizondo M, et al. Validity of the COPCORD core questionnaire as a classification tool for rheumatic diseases. J Rheumatol Suppl. 2011;86(0):31-5. https://doi.org/10.3899/jrheum.100955.

10. National Census of Population and Housing: National Amar Institute; 2011 [Available from: https://www.amar.org.ir/\%D8\%AF\%D8\%A7\%D8\%AF\%D9\% 87\%D9\%87\%D8\%A7-\%D9\%88-\%D8\%A7\%D8\%B7\%D9\%84\%D8\%A7\%D8\% B9\%D8\%A7\%D8\%AA-\%D8\%A2\%D9\%85\%D8\%A7\%D8\%B1\%DB\%8C/\%D8\%A C\%D9\%85\%D8\%B9\%DB\%8C\%D8\%AA-\%D9\%88-\%D9\%86\%DB\%8C\%D8\%B1\% D9\%88\%DB\%8C-\%DA\%A9\%D8\%A7\%D8\%B1/\%D8\%AC\%D9\%85\%D8\%B9\% DB\%8C\%D8\%AA\#5581721\%2D\%2D. Accessed 20 Mar 2021.

11. Faezi ST, Baghdadi A, Nejadhosseinian M, Moradi-Lakeh M, Yekaninejad MS, Holakoui $\mathrm{K}$, et al. Health-care access and utilization among individuals with low back pain in Iran: a WHO-ILAR COPCORD study. BMC Health Serv Res. 2020;20(1):1-7

12. Kiafar M, Faezi ST, Kasaeian A, Baghdadi A, Kakaei S, Mousavi SA, et al. Diagnosis of Behçet's disease: clinical characteristics, diagnostic criteria, and differential diagnoses. BMC Rheumatol. 2021;5(1):1-7.

13. Literacy and higher eduation in Iran: National Amar Institute; 2018 [Available from: https://www.amar.org.ir/\%D9\%BE\%D8\%A7\%DB\%8C\%DA\%AF\%D8\%A 7\%D9\%87-\%D9\%87\%D8\%A7-\%D9\%88-\%D8\%B3\%D8\%A7\%D9\%85\%D8\%A 7\%D9\%86\%D9\%87-\%D9\%87\%D8\%A7/\%D8\%B3\%D8\%B1\%DB\%8C\%D9\%87\% D8\%A7\%DB\%8C-\%D8\%B2\%D9\%85\%D8\%A7\%D9\%86\%DB\%8C/agentType/ ViewType/PropertyTypeID/1890. Accessed 20 Mar 2021

14. Muirden K, Valkenburg H, Hopper J, Guest C. The epidemiology of rheumatic diseases in Australia. Tokyo: APLAR Rheumatology; Churchill Livingstone; 1992. p. 409-10.

15. Al-Awadhi A, Olusi S, Moussa M, Shehab D, Al-Zaid N, Al-Herz A, et al. Musculoskeletal pain, disability and health-seeking behavior in adult Kuwaitis using a validated Arabic version of the WHO-ILAR COPCORD Core questionnaire. Clin Exp Rheumatol. 2004;22(2):177-83.

16. Pelaez-Ballestas I, Sanin LH, Moreno-Montoya J, Alvarez-Nemegyei J, BurgosVargas R, Garza-Elizondo M, et al. Epidemiology of the rheumatic diseases in Mexico. A study of 5 regions based on the COPCORD methodology. J Rheumatol Suppl. 2011;86(0):3-8. https://doi.org/10.3899/jrheum.100951.

17. Minaur N, Sawyers S, Parker J, Darmawan J. Rheumatic disease in an Australian Aboriginal community in North Queensland, Australia. A WHOILAR COPCORD survey. J Rheumatol. 2004;31(5):965-72.

18. Haq SA, Darmawan J, Islam MN, Uddin MZ, Das BB, Rahman F, et al. Prevalence of rheumatic diseases and associated outcomes in rural and urban communities in Bangladesh: a COPCORD study. J Rheumatol. 2005; 32(2):348-53.

19. Senna ER, De Barros ALP, Silva EO, Costa IF, Pereira LVB, Ciconelli RM, et al. Prevalence of rheumatic diseases in Brazil: a study using the COPCORD approach. J Rheumatol. 2004;31(3):594-7.

20. Dai S-M, Han X-H, Zhao D-B, Shi Y-Q, Liu Y, Meng J-M. Prevalence of rheumatic symptoms, rheumatoid arthritis, ankylosing spondylitis, and gout in Shanghai, China: a COPCORD study. J Rheumatol. 2003;30(10):2245-51.

21. Wigley R, Zhang N, Zeng Q, Shi C-S, Hu D, Couchman K, et al. Rheumatic diseases in China: ILAR-China study comparing the prevalence of rheumatic symptoms in northern and southern rural populations. J Rheumatol. 1994; 21(8):1484-90.

22. Reyes GL, Guibert MT, Hernández AM, González ZO, Alcocer JV, Cardiel M. Prevalence of musculoskeletal complaints and disability in Cuba. A community-based study using the COPCORD core questionnaire. Clin Exp Rheumatol. 2000;18(6):739-42.

23. Obregón-Ponce A, Iraheta I, García-Ferrer H, Mejia B, García-Kutzbach A. Prevalence of musculoskeletal diseases in Guatemala, Central America: the COPCORD study of 2 populations. JCR. 2012;18(4):170-4. https://doi.org/10.1 097/RHU.0b013e3182583803.

24. Darmawan J, Valkenburg HA, Muirden KD, Wigley RD. Epidemiology of rheumatic diseases in rural and urban populations in Indonesia: a World Health Organisation international league against rheumatism COPCORD study, stage I, phase 2. Ann Rheum Dis. 1992;51(4):525-8. https://doi.org/1 $0.1136 /$ ard.51.4.525

25. Joshi VL, Chopra A. Is there an urban-rural divide? Population surveys of rheumatic musculoskeletal disorders in the Pune region of India using the COPCORD Bhigwan model. J Rheumatol. 2009;36(3):614-22. https://doi. org/10.3899/jrheum.080675.

26. Chaaya M, Slim ZN, Habib RR, Arayssi T, Dana R, Hamdan O, et al. High burden of rheumatic diseases in Lebanon: a COPCORD study. Int J Rheum Dis. 2012;15(2):136-43. https://doi.org/10.1111/j.1756-185X.2011.01682.x.

27. Veerapen K, Wigley RD, Valkenburg H. Musculoskeletal pain in Malaysia: a COPCORD survey. J Rheumatol. 2007;34(1):207-13.

28. Farooqi A, Gibson T. Prevalence of the major rheumatic disorders in the adult population of North Pakistan. Br J Rheumatol. 1998;37(5):491-5. https://doi.org/10.1093/rheumatology/37.5.491.

29. Dans L, Tankeh-Torres S, Amante C, Penserga E. The prevalence of rheumatic diseases in a Filipino urban population: a WHO-ILAR COPCORD study. World Health Organization. International league of associations for rheumatology. Community oriented Programme for the control of the rheumatic diseases. J Rheumatol. 1997;24(9):1814-9.

30. Chaiamnuay P, Darmawan J, Muirden K, Assawatanabodee P. Epidemiology of rheumatic disease in rural Thailand: a WHO-ILAR COPCORD study. Community oriented Programme for the control of rheumatic disease. $J$ Rheumatol. 1998;25(7):1382-7.

31. Hoa TTM, Darmawan J, Le Chen S, Van Hung N, Nhi CT, An TN, et al. Prevalence of the rheumatic diseases in urban Vietnam: a WHO-ILAR COPCORD study. J Rheumatol. 2003;30(10):2252-6.

32. Litwic A, Edwards MH, Dennison EM, Cooper C. Epidemiology and burden of osteoarthritis. Br Med Bull. 2013;105(1):185-99. https://doi.org/10.1093/ bmb/lds038.

33. Davatchi F, Chams-Davatchi C, Shams H, Nadji A, Faezi T, Akhlaghi M, et al. Adult Behcet's disease in Iran: analysis of 6075 patients. Int J Rheum Dis. 2016;19(1):95-103. https://doi.org/10.1111/1756-185X.12691.

34. Davatchi F, Chams-Davatchi C, Shams H, Shahram F, Nadji A, Akhlaghi M, et al. Behcet's disease: epidemiology, clinical manifestations, and diagnosis Expert Rev Clin Immunol. 2017;13(1):57-65. https://doi.org/10.1080/1744 666X.2016.1205486.

35. Baghdadi S, Mortazavi SMJ, Baghdadi T. The ever-elusive concept of clinical judgment. J Pediatr Orthop. 2020;41(1):e100-1.

\section{Publisher's Note}

Springer Nature remains neutral with regard to jurisdictional claims in published maps and institutional affiliations.

Ready to submit your research? Choose BMC and benefit from:

- fast, convenient online submission

- thorough peer review by experienced researchers in your field

- rapid publication on acceptance

- support for research data, including large and complex data types

- gold Open Access which fosters wider collaboration and increased citations

- maximum visibility for your research: over $100 \mathrm{M}$ website views per year

At BMC, research is always in progress.

Learn more biomedcentral.com/submissions 